\title{
Carotenoids and Photosynthesis - Regulation of Carotenoid Biosyntesis by Photoreceptors
}

\author{
Claudia Stange and Carlos Flores \\ Universidad de Chile \\ Chile
}

\section{Introduction}

Carotenoids are isoprenoid molecules of 40 carbons which are synthesized in a wide variety of photosynthetic (plants, algae) and non photosynthetic (some fungi and bacteria) organisms. So far, over 750 carotenoid structures are known, and these are divided into nonoxygenated molecules designated as carotenes and into oxygenated carotenoids referred to as xanthophylls.

In photosynthetic organisms, carotenoids are synthesized in the plastids, such as chloroplasts. They are localized and accumulated in the thylakoid membranes of chloroplasts (Cunningham \& Gantt, 1998), near the reaction center of photosystem II in the light harvesting complexes (LHC), along with other pigments such as chlorophyll $a$ and $b$. Carotenoids act as accessory pigments in the LHC, where they absorb light in a broader range of the blue spectrum $(400-500 \mathrm{~nm})$ than chlorophyll. Carotenoids transfer the absorbed energy to chlorophyll $a$ during photosynthesis (Britton, 1995). Carotenoids also protect plant cells from photo-oxidative damage as a result of their antioxidant characteristic giving by the conjugate bonds of the polyene chain (Britton, 1995; Britton et al., 1998). In this context carotenoids absorb the excess of energy from reactive oxygen species (ROS) and quench singlet oxygen produced from the chlorophyll triplet in the reaction center of photosystem II (Telfer, 2005). Carotenoids also protect the plant from photo-oxidative damage through thermal dissipation by means of the xanthophyll cycle (Baroli \& Nigoyi, 2000). This process occurs when excessive light increases the thylakoid $\Delta \mathrm{pH}$, which activatates the enzyme violaxanthin de-epoxidase (VDE), converting violaxanthin to zeaxanthin. Zeaxanthin molecules and protons may change the conformation in the LHC, favoring the thermal dissipation.

Carotenoids are also synthesized and accumulated in chromoplasts, plastids that accumulate pigments in flowers, fruits and storage roots. Carotenoids are stored in lipid bodies or in crystalline structures inside the chromoplasts where they are more stable because they are protected from light (Vishnevetsky et al., 1999). In addition, carotenoids are precursors for apocarotenoids such as the phytohormones abscisic acid (ABA) and stringolactones. ABA is involved in dormancy, development and differentiation of plant embryos, stomata open-closure and in tolerance to abiotic stress (Crozier et al., 2000). The stringolactones act as shoot branching inhibitor hormones. Also they are involved in plant signaling to both harmful (parasitic weeds) and beneficial (arbuscular mycorrhizal fungi) rhizosphere residents (Walter et al, 2010). 
In flowers and fruits, the presence of carotenoids serve also to attract pollinators and seed dispersal agents by the intense yellow, orange and red colors that they provide to these organs (Grotewold, 2006).

Animals are not able to synthesize carotenoids, so they have to be included in their diet. In animals, carotenoids are precursors of vitamin A (retinal) and retinoic acid, which play essential roles in nutrition, vision and cellular differentiation, respectively (Krinsky et al., 1994). These molecules have also antioxidant properties (Bartley \& Scolnik, 1995) and therefore, oxidative damage, associated with several pathologies, including aging (Esterbauer et al., 1992), carcinogenesis (Breimer, 1990) and degenerative processes in humans, among others, can be resisted by the ingestion of carotenoids (Rao and Rao, 2007; von Lintig 2010).

\section{Biosynthesis of carotenoid in plants}

Carotenogenic genes are encoded in the nuclear genome and the synthesized proteins are targeted as preproteins to the plastids, where they are post-translationally processed.

Chlorophyll, carotenoids, and prenylquinones are key molecules that share early steps in the biosynthesis and directly derive from the plastidic isoprenoid biosynthetic pathway. This pathway starts within the 2-C-methyl-D-erythritol-4-phosphate (MEP) which provides isopentenylpyrophosphate (IPP) for the synthesis of the primal intermediate geranylgeranyl diphosphate (GGDP). The MEP pathway is involved in the IPP biosynthesis for plastidial isoprenodid, and the mevalonate (MEV) pathway is required for the synthesis of IPP for cytoplasmic sterols (brassinoesteroids, cytoquinins, ubiquinones, Figure 1). Despite these biosynthetic routes appear as independent and compartmentalized, a regulated metabolic cross-talk has been reported between them (Flügge \& Gao, 2005).

The first step of the MEP pathway condenses glyceraldehyde- 3-phosphate and pyruvate-a reaction catalyzed by 1-deoxy-D-xylulose 5-phosphate synthase (DXS)- to produce deoxy-Dxylulose 5-phosphate (DOXP). Then, a reductive isomerization by a DOXP reductoisomerase (DXR) yields MEP; the introduction of a cytidyl moiety by 2-C-methyl-D-erythritol 4phosphate cytidylyl transferase (CMS) produces 4-(cytidine 5'-diphospho)-2-C-methyl-Derythritol that is further phosphorylated by 4-(cytidine $5^{\prime}$-diphospho)- 2-C-methyl-Derythritol kinase (CMK) and then cyclised by 2-C-methyl-Derythritol 2,4-cyclodiphosphate synthase (MCS) to form 2C-methyl-D-erythritol 2,4-cyclo-diP. The final two reactions leading to IPP and DMAPP are carried out by (E)-4-hydroxy-3-methylbut-2-enyl diphosphate synthase (HDS) and reductase (HDR), respectively. All the enzymes of the MEP pathway reside in the stroma. Functional data suggest that the enzymes responsible for the biosynthesis of IPP and DMAPP via the MEP pathway in plants are soluble and localized to plastids (Lange \& Ghassemian, 2003). IPP molecules synthesized in the plastids are isomerized to the allylic isomer, dimethylallyl pyrophosphate (DMAPP) through IPP isomerase (IPI). Three molecules of IPP condense with DMAPP to generate geranylgeranyl pyrophosphate (GGPP), in a process involving GGPP synthase (GGPPS, Figure 1). GGPPS is a central intermediate in the synthesis of plastidic isoprenoids: chlorophylls (phytyl sidechain), carotenoids and prenylquinones (isoprenoid side-chains, Figure 1).

For chlorophyll biosynthesis, the enzyme geranylgeranyl reductase (GGDR) catalyzes the formation of phytyl pyrophosphate (Phytul-PP) from GGPP and chlorophyll synthase (CHLG) catalyses the synthesis of chlorophyll $a$ from Phytyl-PP and chlorophyllide (Figure 1). Chlorophyll $\mathrm{a}$ and $\mathrm{b}$ are precursors for tocopherols (Joyard et al. 2009). 


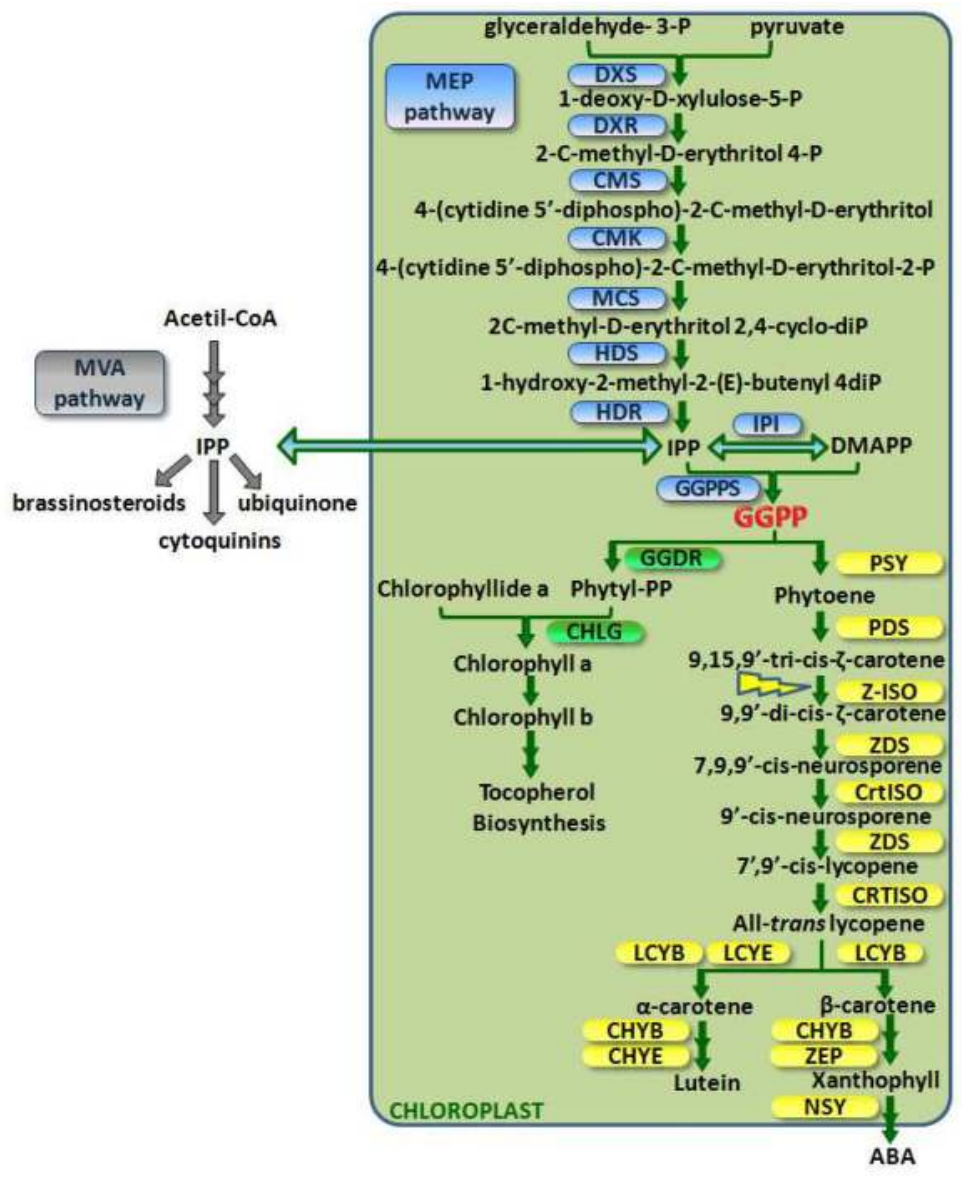

Fig. 1. Scheme of the Isoprenoid Biosynthetic Pathways in Plants. The non-mevalonate pathway (MEP) takes place in plastids and the mevalonate route (MEV) ocurrs in the cytoplasm of the cell. Isopentenylpyrophosphate (IPP) and geranylgeranyl pyrophosphate (GGPP) are key metabolites in the biosynthesis of chlorophylls and carotenoids.

Abbreviations: 2-C-methyl-D-erythritol-4-phosphate (MEP), 1-deoxy-D-xylulose-5phosphate synthase (DXS), 1-deoxy-D-xylulose 5-phosphate reductoisomerase (DXR), 2Cmethyl-D-erythritol 4-phosphate cytidyltransferase (CMS), 4-(cytidine 5\#-diphospho)-2-Cmethyl-D-erythritol kinase (CMK), 2C-methyl-D-erythritol 2,4-cyclodiphosphate synthase (MCS), 1-hydroxy-2-methyl-2-(E)-butenyl 4-diphosphate synthase (HDS), 1-hydroxy-2methyl-2-(E)-butenyl 4-diphosphate reductase (HDR), isopentenyl pyrophosphate isomerase (IPI), dimethylallylpyrophosphate (DMAPP), geranylgeranyl pyrophosphate syntase (GGPPS), phytoene synthase (PSY), phytoene desaturase (PDS), $\zeta$-carotene isomerase (ZISO), $\zeta$-carotene desaturase (ZDS), carotenoid isomerase (CrtISO), lycopene $\beta$ cyclase (LCYB), lycopene $\varepsilon$ cyclase (LCYE), $\beta$-carotene hydroxylase (CHYB), $\varepsilon$-carotene hydroxylase (CHYE), zeaxanthin epoxidase (ZEP), neoxanthin synthase (NSY), abscisic acid (ABA), geranylgeranyl reductase (GGDR), Chlorophyll synthetase (CHLG), light 2 . 
With regard to the carotenoid pathway, two molecules of GGPP give rise to the colorless phytoene by means of phytoene synthase (PSY, Figure 1). The biosynthesis continues with the desaturation of phytoene to produce the pink-colored trans-lycopene. These reactions are catalyzed by two desaturases and two isomerases. The first desaturase, phytoene desaturase (PDS), catalyzes the biosynthesis of 9,15,9'-tri-cis- $\zeta$-carotene, substrate of the 15cis- $\zeta$-carotene isomerase (Z-ISO) to produce $9,9^{\prime}$-di-cis- $\zeta$-carotene. After the 15-cis- $\zeta$ carotene isomerization, the second desaturase termed $\zeta$-carotene desaturasa (ZDS) leads to the formation of 7,9,9'-cis-neurosporene and $7^{\prime}, 9^{\prime}$-cis-lycopene. Finally, the carotene isomerasa (CRTISO) catalyzes the isomerization of this compound resulting in all-trans lycopene (Isaacson et al., 2004; Chen et al., 2010). Although isomerization can be mediated by light, carotenoid biosynthesis in "dark grown" tissues such as roots and etiolates leaves required Z-ISO and CRTISO enzymes.

Subsequently, lycopene is transformed into different bicyclic molecules by means of lycopene cyclases. Lycopene- $\beta$-cyclase (LCYB) converts lycopene into $\gamma$-carotene and afterward to $\beta$-carotene. Lycopene is also cyclized by lycopene- $\varepsilon$-cyclase (LCYE) and by LCYB toproduce a-carotene. The $\beta$-carotene is hydroxylated by the enzyme $\beta$-carotene hydroxylase $(\mathrm{C} \beta \mathrm{Hx}, \mathrm{CRTZ})$ to give rise zeaxanthin, while the hydroxylation of a-carotene by the $\varepsilon$-carotene hydroxylase $(\mathrm{C} \varepsilon \mathrm{Hx})$ and $\mathrm{C} \beta \mathrm{Hx}$ results in the formation of lutein. Abscisic acid is synthesized in the cytoplasm at the end of the pathway by the cleavage of violaxanthin and neoxanthin by carotenoid cleavage dioxygenases (CDE and NCED, Cunningham, 2002).

Some carotenoid enzymes act in multienzyme complexes in the stroma (isopentenyl pyrophosphate isomerase (IPI), geranylgeranyl pyrophosphate synthase (GGPPS) and phytoene synthase (PSY) and others are associated with the thylakoid membrane (phytoene desaturase (PDS), z-carotene desaturase (ZDS), lycopene $\beta$-cyclase (LCYB) and lycopene $\varepsilon$ cyclase (LCYE) (Cunningham \& Gantt, 1998).

\section{Regulation of the carotenogenic pathway}

Due to the importance of carotenoids for plant and animal health, carotenoid biosynthesis regulation has been studied for the last 40 years both at the pure and applied levels. Nearly all carotenogenic genes in diverse plant species, algae, fungi and bacteria have been identified and characterized (Cunningham \& Gantt, 1998; Cunningham, 2002; Howitt \& Pogson, 2006; Cazzonelli \& Pogson, 2010). The knowledge generated has been used to improve the nutritional value of several organisms, preferentially to metabolically engineer $\beta$-carotene and ketocarotenoid formation in plants (Ye et al., 2000; Davuluri et al., 2005; Aluru et al., 2008; Apel \& Bock, 2009).

The regulation of carotenoid biosynthesis has been studied in photosynthetic organs (leaves) and in non-photosynthetic organs (fruits, flowers) of traditional plant models such as Arabidopsis thaliana, Nicotiana tabacum (tobacco) and Solanum lycopersicon (tomato) (Römer and Fraser, 2005; Howitt \& Pogson, 2006).

Almost all of these studies show that carotenogenic genes are expressed in photosynthetic organs exposed to different light qualities, during the transition of etioplasts to chloroplasts (de-etiolation) which correlates with a high and concomitant increase in the carotenoid and chlorophyll levels (Römer \& Fraser, 2005; Toledo-Ortiz et al., 2010).

During these processes, carotenogenic gene expression is mostly regulated at the transcriptional level mediated by photoreceptors such as the family of phytochromes 
(PHYA-PHYE), cryptochromes (CRY) and phototropins. The reaction catalysed by psy has been shown to be the rate limiting step of carotenoid biosynthesis in plants and most studies on psy have been focused on the induction of its transcription by PHY and CRY during plant de-etiolation in A. thaliana, maize, tomato and tobacco. The expression of other carotenogenic genes such as lcyb, bhx, zep y vde is also induced in the presence of white light or during plant de-etiolation (Simkin et al., 2003; Woitsch \& Römer, 2003; Briggs \& Olney, 2001; Franklin et al., 2005; Briggs et al., 2007, Toledo-Ortiz et al., 2010).

\subsection{Carotenoid gene activation mediated by photoreceptors in plants}

Plant photoreceptors, include the family of phytochromes (PHYA-PHYE) that absorb in the red and far red range and cryptochromes (CRY) and phototropins that absorb in the blue and UV-A range (Briggs and Olney, 2001; Franklin et al., 2005; Briggs et al., 2007).

Phytochrome (PHY) is the most characterized type of photoreceptor and their photosensitivity is due to their reversible conversion between two isoforms: the Pr isoform that absorbs light at $660 \mathrm{~nm}$ (red light) resulting in its transformation to the Pfr isoform that absorbs light radiation at $730 \mathrm{~nm}$ (far red). Once Pr is activated, it is translocated to the nucleus as a Pfr homodimer or heterodimer (Franklin et al., 2005; Sharrock \& Clack, 2004; Huq et al., 2003;) where it accumulates in subnuclear bodies, called speckles (Nagatani, 2004). PHY acts as irradiance sensor through its active Pfr form, contributing to the regulation of growth and development in plants (Franklin et al., 2007). A balance between these two isoforms regulates the light-mediated activation of signal transduction in plants (Bae and Choi, 2008), Figure 2.

The signal transduction machinery activated by PHYA and PHYB promotes the binding of transcription factors such as HY5, HFR1 and LAF1 and the release of PIFs factors from light responsive elements (LREs) located in the promoter of genes that are up regulated during the de-etiolation process, such as the psy gene. The most common type of LREs that are present in genes activated by light are the ATCTA element, the G box1 (CACGAG) and G box (CTCGAG). PHYA, PHYB and CRY1, can also activate the Z-box (ATCTATTCGTATACGTGTCAC), another LRE present in light inducible promoters (Yadav et al., 2002). In A.thaliana, it has been shown that PHYA, but not PHYB, plays a role in the transcriptional induction of psy by promoting the binding of HY5 to white, blue, red and far red light responsive elements (LREs) located in its promoter (von Lintig et al., 1997). The involvement of the b-zip transcription factor HY5 in tomato carotenogenesis was proven with LeHY5 transgenic tomatoes that carry an antisense sequence or RNAi of the HY5 transcription factor gene. The transgenic Lehy5 antisense plants contained $24-31 \%$ less leaf chlorophyll compared with non-transgenic plants (Liu et al., 2004), while, immature fruit from Lehy5 RNAi plants exhibited an even greater reduction in chlorophyll and carotenoid accumulation.

Photosynthetic development and the production of chlorophylls and carotenoids are coordinately regulated by phytochrome -interacting factor (PIF) family of basic helix-loophelix transcription factors (bHLH, Shin et al., 2009; Leivar et al. 2009) PIFs are negative regulators of photomorphogenesis in the dark. In darkness, PIF1 directly binds to the promoter of the psy gene, resulting in repression of its expression. Once etiolated seedlings are exposed to $\mathrm{R}$ light, the activated conformation of PHY, the Pfr, interacts and phosphorylates PIF, leading to its proteasome-mediated degradation (Figure 2). Lighttriggered degradation of PIFs results in a rapid de repression of psy gene expression and a 
burst in the production of carotenoids in coordination with chlorophyll biosynthesis and chloroplast development, leading to an optimal transition to the photosynthetic metabolism (Toledo-Ortíz et al., 2010).

A

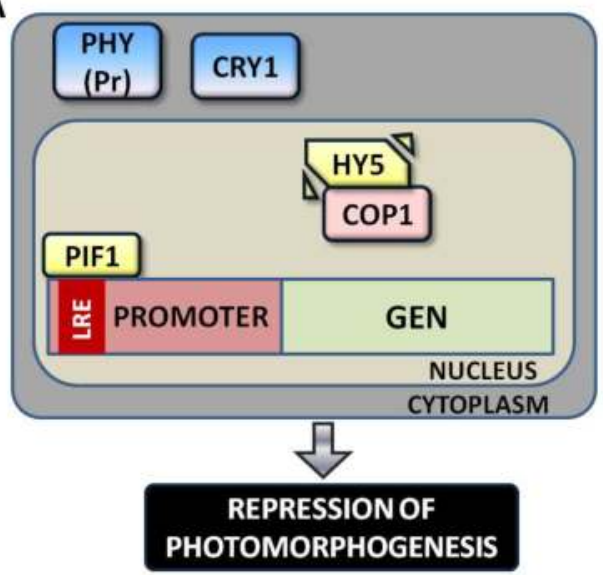

B

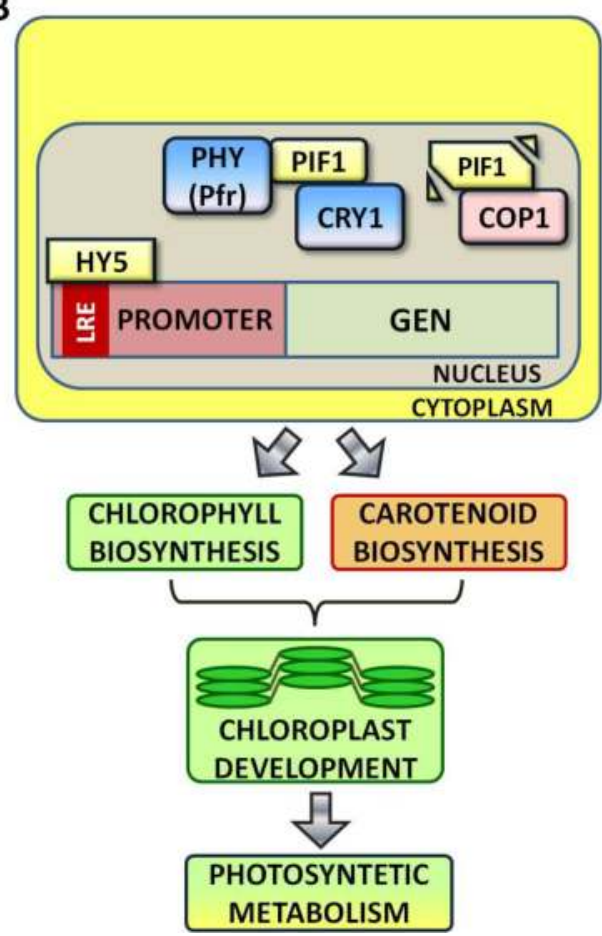

Fig. 2. Ligh-mediated activation of the signal transduction involved in photomorphogenesis in plants. The transition from dark conditions (A) to light conditions (B) allows the photosynthetic metabolism. Abbreviations: activated phytochromoe (PHYPr), cryptochrome 1 (CRY1), transcription factor LONG HYPOCOTYL 5 (HY5), constitutive photomorphogenic 1 (COP1), phytochrome interacting factor (PIF1), light response element (LRE).

Microarray transcriptome analysis during seedling deetiolation indicated that the majority of the gene expression changes elicited by the absence of the PIFs in dark grown pifq seedlings (pif1 pif3 pif4 pif5 quadruple mutants) are normally induced by prolonged light in wild-type seedlings, such as the induction of numerous photosynthetic genes related to the biogenesis of active chloroplasts, auxin, gibberellins (GA), cytokinin and ethylene hormone pathway-related genes, potentially mediating growth responses and metabolic genes involved in the transition from heterotrophic to autotrophic growth.

Besides, other functions associated with PIFs have been described as: i) regulating seed germination; dormant Arabidopsis seeds require both light activation of the phytochrome system and cold treatment (stratification) to induce efficient germination. PIF1 repress germination in the dark and exerts this function, at least in part, by repressing the 
expression of the key GA-biosynthetic genes GA3ox1 and GA3ox2 and promoting the expression of the GA catabolic genes. PIF1 also promotes the expression of the abscisic acid (ABA)-biosynthetic genes, and represses the expression of the ABA catabolic gene, resulting in high ABA levels. PIF4 and PI5 also promote ii) Shade Avoidance Syndrome (SAS); the abundance of these proteins increases rapidly upon transfer of white-light grown seedlings to simulated shade. Pif4, pif5 and pif4 pif5 mutants have reduced hypocotyl-elongation and marker-gene responsiveness to this signal compared with wild type (Leivar \& Quail, 2011).

The cryptochrome CRY, another type of photoreceptor, is also involved in carotenoid light mediated gene activation. Phytochrome and cryptochrome signal transduction events are coordinated (Casal, 2000); PHYA phosphorylates cryptochrome in vitro (Ahmad et al., 1998) and blue and UV-A light trigger the phosphorylation of CRY1 and CRY2 (Shalitin et al., 2002; Shalitin et al., 2003). CRY1 localizes in the cytoplasm during darkness and when plants are exposed to light, CRY1 is exported to the nucleus (Guo et al., 1999; Yang et al., 2000; Schepens et al., 2004). CRY2 which belongs to the same family as CRY1, is localized in the nucleus of plant cells during both light and dark periods (Guo et al., 1999). Overexpression of cry2 in tomato causes repression of lycopene cyclase genes, resulting in an overproduction of flavonoids and lycopene in fruits (Giliberto et al. 2005). It has been reported that zeaxanthin acts as a chromophore of CRY1 and CRY2, leading to stomatal opening when guard cells are exposed to light (Briggs, 1999). The blue/green light absorbed by these photoreceptors induces a conformational change in the zeaxanthin molecule, resulting in the formation of a physiologically active isomer leading to the opening and closing of stomata (Talbott et al., 2002).

CRY and PHY bind and inactivate COP1 through direct protein-protein contact (Wang et al., 2001; Seo et al., 2004). COP1 is a ring finger ubiquitin ligase protein associated with the signalosome complex involved in protein degradation processes via the $26 \mathrm{~S}$ proteasome (Osterland et al., 2000; Seo et al., 2003). During darkness, COP1 triggers degradation of transcription factors committed in light regulation, such as HY5 and HFR1 (Yang et al., 2001; Holm et al., 2002; Yanawaga et al., 2004) whose colocalize with COP1 in nuclear bodies and are marked for post-translational degradation during repression of photomorphogenesis (Ang et al., 1998; Jung et al., 2005). Light promotes conformational changes of COP1, inducing the release of photomorphogenic transcription factors. Once these factors are released, they accumulate and bind to LREs located in the promoters of genes activated by light (Wang et al., 2001;Lin \& Shalitin, 2003, Figure 2). Transgenic tomatoes over expressing a Lecop1 RNAi have a reduced level of cop1 transcripts and significantly higher leaf and fruit chlorophyll and carotenoid content than the corresponding non-transformed controls (Liu et al. 2004),

The UV-damaged DNA binding protein 1 (DDB1) and the de-etiolated-1 (DET1) factors are also negative regulators of light-mediated gene expression, they interact with COP1 and other proteins from the signalosome complex, and lead to ubiquitination of transcription factors (Osterlund et al., 2000; Yanawaga et al., 2004). Post transcriptional gene silencing of det1 leads to an accumulation of carotenoids in tomato fruits (Davuluri et al., 2005). Highly pigmented tomato mutants, $h p 1$ and $h p 2$ display shortened hypocotyls and internodes, anthocyanin accumulation, strongly carotenoid colored fruits and an excessive response to light (Mustilli et al., 1999). HP1 and HP2 encode the tomato orthologs of DDB1 and DET1 in A. thaliana, respectively (Liu et al., 2004). Carotenoid biosynthesis in $h p 2$ mutants increased during light treatments, due to the inactivation of the signalosome, decreasing the 
ubiquitination of transcription factors involved in phytochrome/cryptochrome transduction mechanisms.

The involvement of other photoreceptors such as phototropins, phytochrome $\mathrm{C}$ and $\mathrm{E}$ or CRY2 in the activation of carotenogenic genes has been evaluated through mutants. PhyC mutants, revealed that PHYC is involved in photomorphogenesis throughout the life cycle of A. thaliana playing a role in the perception of day length and acting with PHYB in the regulation of seedling de-etiolation in response to constant red light (Monte et al., 2003). As outlined above, regulation of light-mediated gene expression at the transcriptional level is the key mechanism controlling carotenogenesis in the plastids. Nonetheless, Schofield \& Paliyath (2005) demonstrated post-translational control of PSY mediated by phytochrome. In red light exposed seedlings, PHY is activated which lead to an increase in PSY activity (Schofield \& Paliyath, 2005). Therefore, light by means of photoreceptors, regulates carotenoid biosynthesis through transcriptional and post-transcriptional mechanisms.

\subsection{Carotenoid and chlorophyll biosynthesis are simultaneously regulated}

As mentioned previously, carotenoids carry out an essential function during photosynthesis in the antennae complexes of chloroplasts from green organs. Therefore, the regulation of the biosynthesis of chlorophyll and carotenoid biosynthesis are associated in photosynthetic organs (Woitsch \& Römer, 2003; Joyard et al., 2009).

The photosynthetic machinery is composed of large multisubunit protein complexes composed of both plastidial and nuclear gene products, therefore a proper coordination and regulation of photosynthesis-associated nuclear genes (PhANG) and photosynthesisassociated plastidic genes is thought to be critical for proper chloroplast biogenesis. Light and plastidial signals trigger PhANG expression using common or adjacent promoter elements. A plastidial signal may convert multiple light signaling pathways, that perceive distinct qualities of light, from positive to negative regulators of some but not all PhANGs. Part of this remodeling of light signaling networks involves converting HY5, a positive regulator of PhANGs, into a negative regulator of PhANGs. In addition, mutants with defects in both plastid-to-nucleus and CRY1 signaling exhibited severe chlorophyll deficiencies.

Thus, the remodeling of light signaling networks induced by plastid signals is a mechanism that permits chloroplast biogenesis through the regulation of PhANG expression (Rucke et al., 2007)

White light induces a moderate stimulation of the expression of ppox, that encodes for protophorphirine oxidase (PPOX), an enzyme involved in chlorophyll biosynthesis, and simultaneously induces the expression of several carotenogenic genes (lcy $\beta, c \beta h x$, violaxanthin de-epoxidase (vde) and zeaxanthin epoxidase (zep) genes). In addition, the psy gene, the fundamental gene that controls the biosynthesis of carotenoids, is co-expressed with photosynthetic genes that codify for plastoquinone, $\mathrm{NAD}(\mathrm{P}) \mathrm{H}$ deshydrogenase, tiorredoxin, plastocianin and ferredoxin (Meier et al, 2011). Moreover, according to the induction of carotenogenic genes during de-etiolation, chloroplyll genes are also induced (Woitsh \& Römer, 2003) and the inhibition of lycopene cyclase with 2-(4 chlorophenylthiotriethyl-amine (CPTA) leads to accumulation of non-photoactive protochlorophyllide $a$ (La Rocca et al., 2007). Also, PIF1 has been shown to bind to the promoter of PORC gene encoding Pchilide oxidoreductase whose activity is to convert Pchlide into chlorophylls (Moon et al., 2008). 
Chlorophyll and carotenoid biosynthesis are also regulated indirectly by light through the redox potential generated during photosynthesis. In this process, plastoquinone acts as a redox potential sensor responsible for the induction of carotenogenic genes, indicating that the biosynthesis of carotenoids is under photosynthetic redox control (Jöet et al., 2002; Steinbrenner \& Linden, 2003; Woitsch \& Römer, 2003).

Different experimental approaches were used to determine the regulatory mechanism in which carotenoid and photosynthetic components are involved to determine the chloroplast biogenesis. Arabidopsis pds3 knockout mutant, or plants treated by norflurazon (NF) exert white tissues (photooxidized plastids) due to inactivation of PDS. The immutans (im) variegation mutant, that has a defect in plastoquinol terminal oxidase IMMUTANS (IM) termed PTOX that transfers electrons from the plastoquinone (PQ) pool to molecular oxygen, presents variegated leaves. Considering the PQ pool as a potent initiator of retrograde signaling, a plausible hypothesis is that PDS activity exerts considerable control on excitation pressure, especially during chloroplast biogenesis when the photosynthetic electron transport chain is not yet fully functional and electrons from the desaturation reactions of carotenogenesis cannot be transferred efficiently to acceptors downstream of the PQ pool (Foudree et al., 2010).

Several different types of electronic interactions between carotenoids and chlorophylls have been proposed to play a key role as dissipation valves for excess excitation energy.

In Arabidopsis, the carotenoids-chlorophyll interactions parameter correlates with the nonphotochemical quenching (NPQ), and the fluorescence quenching of isolated major light-harvesting complex of photosystem II (LHCII). During the regulation of photosynthesis, the carotenoids excitation occurs after selective chlorophylls excitation.

Furthermore, the new possibility to quantify the carotenoids-chlorophyll interactions in real time in intact plants will allow the identification of the exact site of these regulating interactions, using plant mutants in which specific chlorophyll and carotenoide binding sites are disrupted (Bode et al., 2009).

\subsection{Regulation of carotenoid expression in photosynthetic organs}

Light is a stimulus that activates a broad range of plant genes that participate in photosynthesis and photomorphogenesis. Carotenoids are required during photosynthesis in plants and algae and therefore, genes that direct the biosynthesis of carotenoids in these organisms are also regulated by light (von Lintig et al., 1997; Welsch et al., 2000; Simkin et al., 2003; Woitsch \& Römer, 2003, Ohmiya et al., 2006; Briggs et al., 2007).

The process of de-etiolation of leaves has been used to compare the levels of carotenoids and gene expression in dark-grown plants versus plants that were transferred to light after being in darkness. During de-etiolation of A. thaliana, the expression of ggpps and $p d s$ genes are relatively constant, whereas expression of the single copy gene, $p s y$ and $h d r$ are significantly enhanced (von Lintig et al., 1997; Welsch et al., 2000, Botella-Pavía et al., 2004). Evidence indicates that the transcriptional activation of $p s y, d x s$ and $d x r$ is essential for the induction of carotenoid biosynthesis in green organs (Welsch et al., 2003; Toledo-Ortiz et al., 2010).

During de-etiolation of tobacco (Nicotiana tabacum) and pepper, xanthophyll biosynthesis genes are transcriptionally activated after 3 or $5 \mathrm{~h}$ of continuous white-light illumination (Simkin et al., 2003; Woitsch \& Römer, 2003). In A. thaliana and tomato, lcy $\beta$ mRNA expression increases 5 times when seedlings are transferred from a low light to a high light environment (Hirschberg, 2001). With the onset of red, blue or white light illumination, 
significant induction of the expression of carotenogenic genes was documented in etiolated seedlings of tobacco, regardless of the light quality used (Woitsch \& Römer, 2003). The expression level was dependent of phytochrome and cryptochrome activities. However, considerable differences in expression levels were observed with respect to the type of light used to irradiate the seedlings. For example, psy gene expression was significantly induced after continuous red and white light illumination, pointing to an involvement of different photoreceptors in the regulation of their expression (Woitsch \& Römer, 2003). PHY is involved in mediating the up-regulation of $p s y 2$ gene expression during maize (Zea mays) seedling photoinduction ( $\mathrm{Li}$ et al, 2008). Also $L c y \beta, c \beta h x$ and $v d e$ are induced upon red light illumination. However, zep shows similar transcriptional activation in the presence of red or blue light (Woitsch \& Römer, 2003).

Compared to normal carotenogenic gene induction mediated by light, the contribution of photo-oxidation to the amount of carotenoids produced in leaves is also important. Carotenoids are synthesized during light exposure but when light intensity increases from 150 to $280 \mu \mathrm{mol} / \mathrm{m}^{2} / \mathrm{s}$, the rate of photo oxidation is higher than the rate of synthesis and carotenoids are destroyed, reaching a certain basal level (Simkin et al., 2003). The level of expression of some carotenogenic genes is also reduced following prolonged illumination at moderate light intensities (Woitsch \& Römer, 2003). During darkness, when photo oxidation of carotenoids does not occur, biosynthesis of carotenoids in leaves is stopped due principally to the very low level of expression of carotenogenic genes. In C. annum, psy, pds, $z d s$ and $l c y \beta$ genes are down regulated in darkness (Simkin et al., 2003) while in A. thaliana the $p s y$ and $h d r$ are active in darkness only at basal levels (Welsch et al., 2003, Botella-Pavía et al., 2004).

\subsection{Effect of light in non-photosyntetic organs}

Light has not only been analysed in photosynthetic tissue as a regulatory agent. In actual fact, light effect on carotenogenic pathway has been report in a number of species during physiological processes like fruit ripening and flower development (Zhu et al., 2003; Giovanonni, 2004; Adams-Phillips et al., 2004; Ohmiya et al., 2006).

In tomato, normal pigmentation of the fruits requires phytochrome-mediated light signal transduction, a process that does not affect other ripening characteristics, such as flavor (Alba et al., 2000). During tomato fruit ripening, carotenoid concentration increases 10 to 14 times, due mainly to accumulation of lycopene (Fraser et al., 1994). An increase in the synthesis of carotenoids is required during the transition from mature green to orange in tomato fruits. During this process, a coordinated upregulation of $d x s, h d r, p d s$ and $p s y 1$ is observed, whilst at the same time the expression of $l c y \beta, c y c \beta$ and $l c y \varepsilon$ decreased (Fraser et al., 1994; Pecker et al., 1996; Ronen et al., 1999; Lois et al., 2000; Botella-Pavía et al., 2004). Two $l c y \beta$ genes have been identified in tomato, $с y c \beta$ and $l c y \beta$. The first is responsible for carotenoid biosynthesis in chromoplasts whereas $\operatorname{lcy} \beta$ performs this role preferentially in chloroplasts (Ronen et al., 1999). The down regulation of $l c y \beta$ and $c y c \beta$ in tomato during ripening leads to an accumulation of lycopene in chromoplasts of ripe fruits (Pecker et al., 1996; Ronen et al., 1999). In C. апnиum, lcy $\beta$ is constitutively expressed during fruit ripening leading to an accumulation of $\beta$-carotene and the red-pigmented capsanthin (Hugueney et al., 1995). The psy gene also plays a considerable role in controlling carotenoid synthesis during fruit development and ripening (Fraser et al., 1999, Giuliano et al., 1993) and during flower development (Zhu et al., 2002, Zhu et al., 2003). In tomato, two distantly-related 
genes, psy1 and psy2 code for phytoene synthase, and the former was found to be transcriptionally activated only in petals and ripening tomato fruits after continuous blue and white-light illumination (Welsch et al., 2000; Schofield \& Paliyath, 2005; Giorio et al., 2008). Transgenic tomato plants expressing an antisense fragment of psy 1 showed a $97 \%$ reduction in carotenoid levels in the fruit, while leaf carotenoids remained unaltered due to the expression of $p s y 2$ (Fraser et al., 1999). psy2 is expressed in all plant organs, preferentially in tomato leaves and petals (Giorio et al., 2008), but in green or ripe fruits it is only expressed at low levels (Bartley \& Scolnik, 1993; Fraser et al., 1999; Giorio et al., 2008). psy1 is also induced in the presence of ethylene, the major senescence hormone implicated in fruit ripening, indicating that PSY is a branch point in the regulation of carotenoid synthesis (Lois et al., 2000).

Evidence emphasizing the importance of light effectors during fruit ripening and carotenoid accumulation was obtained through post-transcriptionally silencing of negative regulators of light signal transduction such as HP1 and HP2, as described above (Mustilli et al., 1999, Liu et al., 2004, Giovannoni, 2004). These high-pigment tomato mutants ( $h p 1$ and $h p 2$ ) have increased total ripe fruit carotenoids and are hypersensitive to light, having little effect on other ripening characteristics, similar to transgenic tomato plants that overexpress CRY (Davuluri et al., 2004; Giliberto et al. 2005).

The up regulation of carotenoid gene expression during ripening has also been reported in other species. In Japanese apricot (Prunus mume) psy, lcy $\beta$, c $\beta h x$ and zep transcripts accumulate in parallel with the synthesis of carotenoids (Kita et al., 2007). In juice sacs of Satsuma mandarin (Citrus reticulata), Valencia orange (C. sinensis) and Lisbon lemon (C. limon) the expression of carotenoid biosynthetic genes such as CitPSY, CitPDS, CitZDS, $\mathrm{CitLCYb}$, CitHYb, and CitZEP increases during fruit maturation, co-ordinately with the synthesis of carotenes and xanthophylls (Kato et al., 2004). In citrus of the "Star Ruby" cultivar, the high level of lycopene was correlated with a decrease in $C \beta H x$ and lcyb2 expression, genes associated to the synthesis of carotenoids in chromoplast (Alquezar et al., 2009). In G. lutea analysis of the expression of carotenogenic genes during flower development and in different plant organs indicated that psy was expressed in flowers concomitant with carotenoid synthesis but not in stems and leaves (Zhu et al., 2002).

Carotenoids are also present in amyloplasts of potato and cereal seeds such as maize and wheat (Triticum aestivum; Panfili et al., 2004, Howitt \& Pogson 2006; Nesterenko \& Sink, 2003). Both potatoes and cereals accumulate low levels of carotenoid in the dark (Nesterenko and Sink, 2003) in contrast to the highly pigmented modified root of carrots.

Daucus carota L. (carrot, $2 \mathrm{n}=18$ ) is a biennal plant whose orange storage or modified root is consumed worldwide. Orange carrot contains high levels of $\alpha$-carotene and $\beta$-carotene (8 $\mathrm{mg} / \mathrm{g}$ dry weight, Fraser, 2004) that together constitute up to $95 \%$ of total carotenoids in the storage root Baranska et al., 2006). The kinetics of the transcript accumulation of some of the carotenogenic genes correlates with total carotenoid composition during the development of storage roots grown in the dark (Clotault et al., 2008).

We are focused in the study of carotenoid regulation in this novel plant model, taken in account that carotenoids in carrot are synthesized in leaves exposed to light, and also in the storage root that develops in darkness. All carotenogenic genes in carrot are expressed in both, leaves and roots during plant development, but the expression level is higher in leaves maybe due the faster exchange rate of carotenoids during photosynthesis (Beisel y et al., 2010). Lcyb1 gene presents the higher increase in transcript level during leaves development and the paralogous genes, $p s y 1$ and $p s y 2$ are differentially expressed during development. 
In roots, the expression of almost all carotenogenic genes are induced during storage root development and it correlates with carotenoid accumulation. In this organ carotenoids are stored in plastoglobuli in the chromoplasts, where they are more photo-stable than in chloroplasts (Merzlyak \& Solovchenko, 2002). Therefore, photo-oxidation does not affect carotenoid content in these organs, even when they are exposed to light.

When roots were exposed to light, they did not develop normally and the expression of almost all genes differs from the pattern obtained in dark-grown roots during development (Figure 3A). In addition, the roots developed in the presence of light have the same carotenoid composition and amount as in leaves (Stange et al., 2008; Fuentes et al., 2011 in preparation). The thin non-orange carrot root also accumulates chloroplasts instead of chromoplasts, as leaves, and the carotenoid gene expression profile is almost the same as those expressed in the photosynthetic organ.

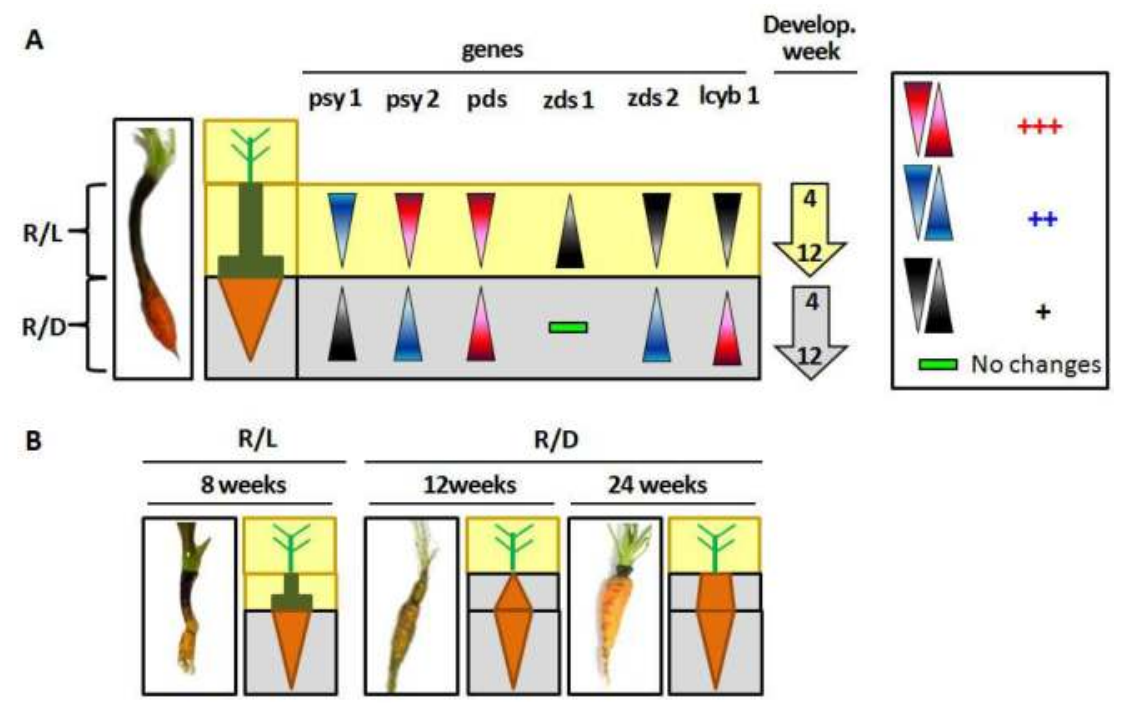

+++: high gene expression level, ++: middle gene expression level, +: low gene expression level. $\Delta$ :

expression increases during development, $V$ : expression decreases during development

Fig. 3. Light affects morphology and carotenogenic gene expression in carrot roots $A$; a comparison of carotenogenic gene expression in roots under light $(\mathrm{R} / \mathrm{L})$ and dark $(\mathrm{R} / \mathrm{D})$ conditions during the developmental process from 4 weeks to 12 weeks. Abbreviations: phytoene synthase 1 (psy 1), phytoene synthase 2 (psy 2), phytoene desaturase (pds), $\zeta$ carotene desaturase 1 (zds1), $\zeta$-carotene desaturase 2 (zds2), lycopene $\beta$ cyclase 1 (lcyb1), Develoment (Develop). B; changes in the phenotype of a 8 weeks old carrot root grown in light $(\mathrm{R} / \mathrm{L})$ and then transferred to dark conditions (R/D) until 12 weeks and 24 weeks. The root normal development is inhibited by light in a reversible manner (Modified from Stange et al., 2008).

Also, when the carrot root of an 8 weeks old plant was transferred from light to darkness, the root started to develop (Figure 3B). Therefore, light alters the morphology and 
development of carrot modified roots in a reversible manner (Stange et al., 2008). Light inhibited storage root development, possibly because some transcriptional or growth factors are repressed, although more extensive studies are needed to investigate this phenomenon.

\section{Conclusion}

Light induces photomorphogenesis, chlorophyll and carotenoid biosynthesis through the signal transduction mediated by photoreceptors such as PHYA, PHYB and CRY in photosynthetic organs. At present, the principal components involved in the carotenogenic pathway have been described in many plant models, but fundamental knowledge regarding to the regulation is still necessary. In fact, psy gene may be the rate limiting step on carotenoid biosynthesis in leaves and also in chromoplasts accumulating organs. In addition, the highly regulated machinery on carotenoid biosynthesis can also be displayed through the organ specificity associated with carotenogenic gene function and their correlation with chlorophyll biosynthesis.

New strategies aimed to elucidate the regulation of carotenoid pathway could be associated with transcriptome analysis which could provide insights into regulatory branch points of the pathway. Conventional studies focused on the identification and characterization of carotenogenic gene promoters could also help to understand the regulation of the expression of the genes in photosynthetic and in non-photosynthetic organs. In fact, light responsive elements (LRE) in such promoters could be associated with transcription factors involved in carotenogenic and chlorophyll gene expression. On the other hand, research focused in the adjustment of the light- mediated signal transduction machinery would also be an effective metabolic approach for modulating chlorophyll and fruit carotenoid composition in economically valuable plants.

\section{Acknowledgements}

Acknowledgements to the Chilean Grant Fondecyt 11080066

\section{References}

Adams-Philips, L.; Barry, C. \& Giovannoni, J. (2004). Signal transduction system regulating fruit ripening. Trends Plant Sci, Vol.9, No.7, (July 2004), pp. 331-338.

Ahmad, M.; Jarillo, JA.; Smirnova O. \& Cashmore, AR. (1998). The CRY1 blue light photoreceptor of Arabidopsis interacts with phytochrome A in vitro. Mol Cell, Vol.1, No.7, (June 1998), pp. 939-948.

Alba, R.; Cordonnier-Pratt MM. \& Pratt LH. (2000). Fruit localized phytochromes regulate lycopene accumulation independently of ethylene production in tomato. Plant Physiol, Vol.123, No.1, (May 2000), pp. 363-370.

Alquézar, B.; Zacarías, L. \& Rodrigo, MJ. (2009). Molecular and functional characterization of a novel chromoplast-specific lycopene $\beta$-cyclase from Citrus and its relation to lycopene accumulation. Journal of Experimental Botany, Vol.60, No.6, (March 2009), pp.1783-97. 
Aluru, M.; Xu, Y.; Guo, R.; Wang, Z.; Li, S.; White, W. \& Rodermel, S. (2008). Generation of transgenic maize with enhanced provitamin A content. J Exp Bot, Vol.59, No.13, (Agust 2008), pp.3551-62.

Ang, LH.; Chattopadhyay, S.; Wei, N.; Oyama, T.; Okada, K.; Batschauer, A. \& Deng, XW. (1998). Molecular interaction between COP1 and HY5 defines a regulatory switch for light control of Arabidopsis development. Mol Cell, Vol.1, No.2, (January), pp.213-222.

Apel, R.; Rock, R. (2009). Enhancement of Carotenoid Biosynthesis in Transplastomic Tomatoes by Induced Lycopene-to-Provitamin A Conversion. Plant Physiol, Vol.151, No.1, (September 2009), pp.59-66.

Averina, NG. (1998). Mechanism of regulation and interplastid localization of chlorophyll biosynthesis. Membr. Cell Biol., Vol.12, No.5, pp.627-643.

Bae, G. \& Choi, G. (2008). Decoding of light signals by plant phytochromes and their interacting proteins. Annu Rev Plant Biol, Vol.59, (June 2008), pp.281-311.

Ballesteros, ML.; Bolle, C.; Lois, LM.; Moore, JM.; Vielle-Calzada, JP.; Grossniklaus, U. \& Chua, N. (2001). LAF1, a MYB transcription activator for phytochrome A signaling. Genes Dev. , Vol.15, No.19, (October), pp.2613-25.

Baranska M, Baranski R, Schulz H, Nothnagel T. (2006). Tissue-specific accumulation of carotenoids in carrot roots. Planta, Vol.224, No.5, (October 2006), pp. 1028-37.

Baroli, I. \& Nigoyi, KK. (2000). Molecular genetics of xanthophylls-dependent photoprotection in green alge and plants. Philos Trans R Soc Lond B Biol Sci. Vol.355, No.1402, (October 2000), pp.1385-94.

Bartley, G. \& Scolnik, P. (1993). cDNA cloning expression during fruit development and genome mapping of PSY2, a second tomato gene encoding phytoene synthase. J Biol Chem, Vol.268, No.34, (December 1993), pp.25718-21.

Bartley, G. \& Scolnik, P. (1995). Plant carotenoids: pigments for photoprotection, visual attraction and human health. Plant Cell, Vol.7, No.7, (July 1995), pp.1032.

Beisel, KG.; Jahnke, S.; Hofmann, D.; Köppchen, S.; Schurr, U. \& Matsubara, S. (2010). Continuous turnover of carotenes and chlorophyll a in mature leaves of Arabidopsis revealed by $14 \mathrm{CO} 2$ pulse-chase labeling. Plant Physiol, Vol.152, No.4, (April 2010), pp.2188 - 99.

Bode, S.; Quentmeier, C.; Liao, P.; Hafi, N.; Barros, T.; Wilk, L,; Bittner, F.; \& Walla, PJ. (2009). On the regulation of photosynthesis by excitonic interactions between carotenoids and chlorophylls. Proc Natl Acad Sci U S A, Vol.106, No.30, (June 2009), pp. 12311-12316.

Botella-Pavía, P.; Besumbes, O.; Phillips, M.; Carretero-Paulet, L.; Boronat, A. \& RodríguezConcepción, M. (2004). Regulation of carotenoid biosynthesis in plants: evidence for a key role of hydroxymethylbutenyl diphosphate reductase in controlling the supply of plastidial isoprenoid precursors. Plant Cell, Vol.40, No.2, (October 2004), pp.188-199.

Breimer, L. (1990). Molecular mechanisms of oxygen radical carcinogenesis and mutagenesis: the role of DNA base damage. Mol. Carcinog., Vol.3, No.4, pp.188-197.

Briggs, W.; Tseng, T.S.; Cho, H-T.; Swartz, T.; Sullivan, S.; Bogomolni, R.; Kaiserli, E. \& Christie, J. (2007). Phototropins and their LOV domains: versatile plant blue-light receptors. J Integr Plant Biol, Vol.49, No.1, (January 2007), pp.4-10. 
Briggs, W. \& Olney, M. (2001). Photoreceptors in plant photomorphogenesis to date. Five phytochromes, two Cryptochromes, one phototropin, and one superchrom. Plant Physiol., Vol.125, No.1, (January 2001), pp.85-88.

Briggs, W. (1999). Blue-light photoreceptors in higher plants. Annu Rev Cell Dev Biol, Vol.15, (November 1999), pp.33-62.

Britton, G. (1995). Regulation of carotenoid formation during tomato fruit ripening and development. J Exp Bot, Vol.53, No.377, (October 1995), pp.2107-2113.

Britton G. (Ed.), Liaaen-Jensen S. (Ed.), Pfander H. (Ed.) (1998). Carotenoids: Biosynthesis and Metabolism (1 edition), Birkhauser Basel, ISBN-10: 3764358297, Switzerland.

Casal, JJ. (2000). Phytochromes, Cryptochromes, phototropin: Photoreceptor interaction in plants. Photochem Photobiol, Vol.71, No.1, (May 2000), pp.1-11.

Cazzonelli, CI. \& Pogson, BJ. (2010). Source to sink: regulation of carotenoid biosynthesis in plants. Trends Plant Sci, Vol.15, No.5, (May 2010), pp. 266 - 274.

Chen, Y.; Li, F. \& Wurtzel, E. (2010) Isolation and Characterization of the S-ISO Gene Encoding a Missing Component of Carotenoid Biosynthesis in Plants. Plant Physiol, Vol. 153, (May 2010) pp. 66-79.

Clotault J.; Peltier, D.; Berruyer, R.; Thomas, M.; Briard, M. \& Geoffriau, E. (2008). Expression of carotenoid biosynthesis genes during carrot root development. J Exp Bot, Vol.59, No.13, (Agust 2008), pp.3563-73

Crozier, A.; Kamiya, Y.; Bishop, G. \& Yolota, T. (2000). Biosynthesis of hormone and elicitor molecules. Pages 865-872. In: B. Buchanan, W. Gruissem, \& R. Jones (eds.), Biochemistry and Molecular Biology of Plants. American Society of Plant Physiologist.

Cunningham, FX. \& Gantt, E. (1998). Genes and enzymes of carotenoid biosynthesis in plants. Annu Rev Plant Physiol Plant Mol Biol, Vol.49, (June 1998), pp.557-583.

Cunningham, FX. (2002). Regulation of carotenoid synthesis and accumulation in plants. Pure Appli Chem, Vol.74, No., (8), pp.1409-17.

Davuluri, GR.; Van Tuinen, A.; Mustilli, AC.; Manfredonia, A.; Newman, R.; Burgess, D.; Brummell, DA.; King, SK.; Palys, J.; Uhlig, J.; Pennings, HM. \& Bowler, C. (2004). Manipulation of DET1 expression in tomato results in photomorphogenic phenotypes caused by post-transcriptional gene silencing. Plant J, Vol.40, No.3, (November 2004), pp.344-354.

Esterbauer, H.; Gebiki, J.; Puhl, H. \& Jurgens, G. (1992). The role of lipid peroxidation and antioxidants in oxidative modification of LDL. Free Radic Biol Med, Vol.13, No.4, (October 1992), pp.341-391.

Flügge, UI. \& Gao, W. (2005). Transport of isoprenoid intermediates across chloroplast envelope membranes. Plant Biol, Vol.7, No.1, (January 2005), pp. 97-97.

Franklin, KA.; Larner, VS. \& Whitelam, GC. (2005). The signal transducing photoreceptor of plants. Int. J. Dev. Biol., Vol.49, No.5-6, pp.653-664.

Franklin, K.; T. Allen, \& G. Whitelam. (2007). Phytochrome A is an irradiance-dependent red light sensor. Plant J, Vol.50, No.1, (April 2007), pp.108-117.

Fraser, PD.; Truesdale, MR.; Bird, CR.; Schuch, W. \& Bramley PM. (1994). Carotenoid biosynthesis during tomato fruit development. Plant Physiol., Vol.105, No.1, (May 1994), pp.405-413. 
Fuentes, P.; Pizarro, L.; Handford, M.; Rodriguez-Concepción, M.\& Stange C (2011). Lightdependent changes in plastid differentiation influence carotenoid gene expression and accumulation in carrot roots.Plant Mol. Biol, under evaluation, July 2011

Foudree, A.; Aluru, M.; \& Rodermel, S. (2010). PDS activity acts as a rheostat of retrograde signaling during early chloroplast biogenesis. Plant Signal Behav, Vol.5, No.12, (December 2010), pp. 1629-1632

Giliberto, L.; Perrotta, G.; Pallara, P.; Weller, JL.; Fraser, PD.; Bramley, PM.; Fiore, A.; Tavazza, M. \& Giuliano, G. (2005). Manipulation of the blue light photoreceptor cryptochrome 2 in tomato affects vegetative development, flowering time, and fruit antioxidant content. Plant Physiol., Vol.137, No.1, (January 2005), pp.199-208.

Giorio, G.; Stigliani, AL. \& D'ambrosio, C. (2008). Phytoene synthase genes in tomato (Solanum lycopersicum L.) - new data on the structures, the deduced amino acid sequences and the expression patterns. FEBS J., Vol.275, No.3, (February 2008), pp.527-535.

Giovannoni, JJ. (2004). Genetic regulation of fruit development and ripening. Plant Cell, Vol.16, Suppl.1, (June 2004), pp.S170-S180.

Giuliano, G.; Bartley, GE. \& Scolnik, PA. (1993). Regulation of carotenoid biosynthesis during tomato development. Plant Cell, Vol.5, No.4, (April 1993), pp.379-387.

Grotewold, E. (2006). The genetics and biochemistry of floral pigments. Annu Rev Plant Biol, Vol.57, (June 2006), pp.761-780.

Guo, H.; Duong, H.; Ma, N. \& Lin, C. (1999). The Arabidopsis blue light receptor cryptochrome 2 is a nuclear protein regulated by a blue light-dependent posttranscriptional mechanism. Plant J, Vol.19, No.3, (August 1999), pp.279-287.

Hirschberg, J. (2001). Carotenoids biosynthesis in flowering plants. Curr Opin Plant Biol, Vol.4, No.3, (June 2001), pp.210-218.

Holm, M.; Ma, LG.; Qu, LJ. \& Deng, XW. (2002). Two interacting bZIP proteins are direct targets of COP1-mediated control of light dependent gene expression in Arabidopsis. Genes Dev. , Vol.16, No.10, (May 2002), pp.1247-59.

Howitt, CA.; \& Pogson, BJ. (2006). Carotenoid accumulation and function in seeds and nongreen tissues. Plant Cell Environ., Vol.29, No.3, (March 2006), pp.435-445.

Hugueney P, Badillo A, Chen HC, Klein A, Hirschberg J, Camara B, Kuntz M. (1995). Metabolism of cyclic carotenoids: a model for the alteration of this biosynthetic pathway in Capsicum annuum chromoplasts. Plant J, Vol.8, No.3, (September 1995), pp. 417-424.

Huq, E.; Al-sady, B. \& Quail, PH. (2003). Nuclear translocation of the photoreceptor phytochrome $\mathrm{B}$ is necessary for its biological function in seedling photomorphogenesis. Plant J, Vol.35, No.5, (September 2003), pp.660-664.

Isaacson, T.; Ohad, I.; Beyer, P. \& Hirschberg, J. (2004). Analysis in vitro of the enzyme CRTISO establishes a poly-cis-carotenoid pathway in plants. Plant Physiol., Vol.136, No.4, (December 2004), pp.4246-4255.

Joët, T.; Genty, B.; Josse, EM.; Kuntz, M.; Cuornac, L. \& Peltier, G. (2002). Involvement of a plastid terminal oxidase in plastoquinone oxidation as evidenced by expression of the Arabidopsis thaliana enzyme in tobacco. J Biol Chem, Vol.277, No.35, (August 2002), pp.31623-31630. 
Joyard, J.; Ferro, M.; Masselon, C.; Seigneurin-Berny, D.; Salvi, D.; Garin, J. \& Rolland, N. (2009) Chloroplast Proteomics and the Compartmentation of Plastidial Isoprenoid Biosynthetic Pathways. Molec Plant, Vol. 2, No. 6, (November 2009), pp. 1154-80

Jung, IC.; Yang, JY.; Seo, HS. \& Chua, NH. (2005). HFRA is target by COP1 E3 ligase for post-transcriptional proteolysis during phytochrome A signaling. Genes Develop, Vol.19, No.5, (March 2005), pp.593-602.

Kato, M.; Ikoma, Y.; Matsumoto, H.; Sugiura, M.; Hyodo, H. \& Yano, M. (2004). Accumulation of carotenoids and expression of carotenoid biosynthetic genes during maturation in citrus fruit. Plant Physiol., Vol.134, No.2, (February 2004),

Ohmiya A, Kishimoto S, Aida R, Yoshioka S, Sumitomo K. (2006). Carotenoid cleavage dioxygenase (CmCCD4a) contributes to white color formation in chrysanthemum petals. Plant Physiol, Vol 142, No.3, (November 2006), pp. 1193 -201.

Krinsky, NI.; Wang, XD.; Tang, G. \& Russell, RM. (1994). Cleavage of $\beta$-carotene to retinoid. In book: in: Retinoids: From Basic Science to Clinical Applications (Livrea, MA \& Vidali, G, Eds.) pp. 21-28, Birkhaüser, Basel , Alemania. ISBN 3-7643-2812-6

La Rocca N, Rascio N, Oster U, Rüdiger W. (2007). Inhibition of lycopene cyclase results in accumulation of chlorophyll precursors. Planta, Vol.255, No.4, (March 2007), pp.1019-29.

Lange, BM. \& Ghassemian, M. (2003). Genome organization in Arabidopsis thaliana: a survey for genes involved in isoprenoid and chlorophyll metabolism. Plant Mol Biol, Vol.51, No.6, (April 2003), pp.925-948.

Leivar P., \& Quail, PH. (2011) PIFs: pivotal components in a cellular signaling hub. Trends Plant Sci, Vol.16, No.1, (January 2011), pp.19-28.

Leivar, P.; Tepperman, J.M.; Monte, E.; Calderon, R.H.; Liu, T.L.; Quail, P.H. (2009) Definition of Early Transcriptional Circuitry Involved in Light-Induced Reversal of PIF-Imposed Repression of Photomorphogenesis in Young Arabidopsis Seedlings. Plant Cell, Vol.21, No.11, (November 2009), pp.3535-53.

Li, F.; Vallabhaneni, R. \& Wurtzel, L. (2008). PSY3, a new member of the phytoene synthase gene family conserved in the poaceae and regulator of abiotic stress-induced root carotenogenesis. Plant Physiol, Vol.146, No.3, (March 2008), pp.1333-45.

Lin, C. \& Shalitin, D. (2003). Cryptochrome structure and signal transduction. Annu Rev Plant Biol, Vol.54, (June 2003), pp.469-96.

Liu, Y.; Roof, S.; Ye, Z., Barry, C.; van Tuinen, A.; Vrebalov, J.; Bowler, C. \& Giovannoni, J. (2004). Manipulation of light signal transduction as a means of modifying fruit nutritional quality in tomato. Proc Natl Acad Sci USA, Vol.101, No.26, (June 2004), pp.9897-9902

Lois, L.; Rodriguez, C.; Gallego, F.; Campos, N. \& Boronat, A. (2000). Carotenoid biosynthesis during tomato fruit development: regulatory role of 1-deoxy-Dxylulose 5-phosphate synthase. Plant J, Vol.22, No.6, (June 2000), pp.503-513.

Meier, S.; Tzfadia, O.; Vallabhaneni, R.; Gehring, C. \& Wurtzel, ET. (2011). A transcriptional analysis of carotenoid, chlorophyll and plastidial isoprenoid biosynthesis genes during development and osmotic stress responses in Arabidopsis thaliana. BMC Syst Biol, Vol. 5, No.77, (May 2011), pp. 1-19.

Merzlyak, MN. \& Solovchenko, AE. (2002). Photostability of pigments in ripening apple fruit: a possible photoprotective role of carotenoids during plant senescence. Plant Sci, Vol.163, No.4, (October 2002), pp.881-888. 
Monte, E.; Alonso, JM.; Ecker, JR.; Zhang, Y.; Li, X.; Young, J.; Austin-Phillips, S. \& Quail, PH. (2003). Isolation and characterization of phyC mutants in Arabidopsis reveals complex crosstalk between phytochrome signaling pathways. Plant Cell, Vol.15, No.9, (September 2003), pp.1962-80.

Moon, J.; Zhu, L.; Shen, H., \& Huq, E. (2008) PIF1 directly and indirectly regulates chlorophyll biosynthesis to optimize the greening process in Arabidopsis. Proc Natl Acad Sci U S A, Vol.105, No.27, (Lujy 2008), pp.9433-38.

Mustilli, A.; Fenzi, F.; Ciliento, R.; Alfano, F. \& Bowler, C. (1999). Phenotype of tomato high pigment-2 mutants is caused for a mutation in the tomato homolog of Deetiolated1. Plant Cell, Vol.11, No.2, (February 1999), pp.145-157.

Nagatani, A. (2004). Light-regulated nuclear localization of phytochromes. Curr Opin Plant Biol, Vol.7, No.6, (December 2004), pp.708-711.

Nesterenko, S. \& Sink, KC. (2003). Carotenoid profiles of potato breeding lines and selected cultivars. HortScience, Vol.38, No.6, (October 2003), pp.1173-77.

Osterlund, MT.; Hardtke, CS.; Wei, N. \& Deng, XW. (2000). Targeted destabilization of HY5 during light-regulated development of Arabidopsis. Nature, Vol.405, No.6785, (May 2000), pp.462-466.

Panfili, G.; Fratianni, A. \& Irano, M. (2004). Improved normal-phase high-performance liquid chromatography procedure for the determination of carotenoids in cereals. $J$ Agric Food Chem, Vol.52, No.21, (October 2004), pp.6373-6377.

Pecker, I.; Gubbay R.; Cunningham, FX. \& Hirshberg, J. (1996). Cloning and characterization of the cDNA for lycopene beta-cyclase from tomato reveal a decrease in its expression during tomato ripening. Plant Mol Biol, Vol.30, No.4, (February 1996), pp.806-819.

Rao, AV. \& Rao, LG.. (2007). Carotenoids and human health. Pharmacological Res, Vol.55, No., (March 2007), pp.207-216.

Römer, S \& Fraser, PD. (2005). Recent advances in carotenoid biosynthesis, regulation and manipulation. Planta, Vol.221, No., (June 2005), pp.305-308.

Ronen, G.; Cohen, M.; Zamir, D. \& Hirshberg, J. (1999). Regulation of carotenoid biosynthesis during tomato fruit development: expression of gene for lycopene epsilon cyclase is down regulated during ripening and is elevated in the mutant delta. Plant J, Vol.17, No.4, (February 1999), pp.341-351.

Ruckle, ME.; DeMarco, SM. Larkin RM. (2007). Plastid Signals Remodel Light Signaling Networks and Are Essential for Efficient Chloroplast Biogenesis in Arabidopsis. The Plant Cell, Vol.19, (December 2007), pp.3944-60.

Schepens, I.; Duek, P. \& Fankhauser, C. (2004). Phytochrome-mediated light signaling in Arabidopsis. Curr Opin Plant Biol, Vol.7, No.5, (October 2004), pp.564-569.

Schofield, A. \& Paliyath, G. (2005). Modulation of carotenoid biosynthesis during tomato fruit ripening through phytochrome regulation of phytoene synthase activity. Plant Physiol Biochem, Vol.43, No.12, (December 2005), pp.1052-1060.

Schmid, VH. (2008). Light-harvesting complexes of vascular plants. Cell Mol Life Sci, Vol.65, No.22, (November 2008), pp.3619-3639

Seo, HS.; Yang, JY.; Ishikawa, M.; Bolle, C.; Ballesteros, ML. \& Chua NH. (2003). LAF1 ubiquitination by COP1 controls photomorphogenesis and is stimulated by SPA1. Nature, Vol.423, No.423, (June 2003), pp.995-999. 
Seo, HS.; Watanabe, E.; Tokutomi, S.; Nagatani, A. \& Chua, NH. (2004). Photoreceptor ubiquitination by COP1 E3 ligase desensitizes phytochrome A signaling. Genes Dev, Vol.18, No.6, (March 2004), pp.617-622.

Shalitin, D.; Yang, H.; Mockler, TC.; Maymon, M.; Guo, H.; Guitelam, GC. \& Lin, C. (2002). Regulation of Arabidopsis cryptochrome 2 by blue light-dependent phosphorylation. Nature, Vol.417, No.6890, (June 2002), pp.763-767.

Shalitin, D.; Yu, X.; Maymon, M.; Mockler, T. \& Lin, C. (2003). Blue light-dependent in vivo and in vitro phosphorylation of Arabidopsis cryptochrome 1. Plant Cell, Vol.15, No.10, (October 2003), pp.2421-2429.

Sharrock, R. \& Clack, T. (2004). Heterodimerization of type II phytochromes in Arabidopsis. Proc Natl Acad Sci USA, Vol.101, No.31, (August 2004), pp.11500-11505.

Shewmaker, CK.; Sheehy, JA.; Daley, M.; Colburn, S. \& Ke, DY. (1999). Seed-specific overexpresion of phytoene synthase: increase in carotenoids and other metabolic effects. Plant J, Vol.20, No.4, (November 1999), pp.401-412.

Shin, J.; Kim, K.; Kang, H.; Zulfugarov, IS.; Bae, G.; Lee, CH.; Lee, D. \& Choi, G. (2009) Phytochromes promote seedling light responses by inhibiting four negativelyacting phytochrome-interacting factors. Proc NatlAcad Sci U S A, Vol.106, No.18, (May 2009), pp.7660-65.

Simkin, AJ.; Zhu, C.; Kuntz, M. \& Sandmann, G. (2003). Light-dark regulation of carotenoid biosynthesis en pepper (Capsicum annuum) leaves. J Plant Physiol, Vol.160, No.5, (May 2003), pp.439-443.

Stange, C.; Fuentes, P.; Handford, M. \& Pizarro, L. (2008). Daucus carota as a novel model to evaluate the effect of light on carotenogenic gene expression. Biol Res, Vol.41, No.3, (April 2008), pp.289-301.

Steinbrenner, J. \& Linden, H. (2003). Light induction of carotenoid biosynthesis genes in the green alga Haematococcus pluvialis: regulation by photosynthetic redox control. Plant Mol Biol 52, Vol., No.2, (May 2003), pp.343-356.

Talbott, L.; Nikolova, G.; Ortíz, A.; Shmayevich, I. \& Zeiger, E. (2002). Green light reversal of blue-light-stimulated stomatal opening is found in a diversity of plant species. Am J Bot, Vol.89, No.2, (February 2002), pp.366-368.

Telfer, A. (2005). Too much light? How beta-carotene protects the photosystem II reaction centre. Photochem Photobiol Sci, Vol.4, No.12, (December 2005), pp.950-956.

Toledo-Ortiz, G.; Huq, E. \& Rodrígurz-Concepción, M. (2010). Direct regulation of phytoene synthase gene expression and carotenoid biosynthesis by Phytochrome-Interacting Factors. Vol.107, No.25, (June 2010), pp. 11626-11631.

Vishnevetsky, M.; Ovadis, M. \& Vainstein, A. (1999). Carotenoid sequestration in plants: the role of carotenoid associated proteins. Trends Plant Sci, Vol.4, No.6, (June 1999), pp. 232-235.

von Lintig J. (2010). Colors with functions: elucidating the biochemical and molecular basis of carotenoid metabolism. Annu Rev Nutr, Vol.30, (August 2010), pp. 35-56.

Von Lintig, J.; Welsch, R.; Bonk, M.; Giuliano, G.; Batschauer, A. \& Kleinig, H. (1997). Lightdependent regulation of carotenoid biosynthesis occurs at the level of phytoene synthase expression and is mediated by phytochrome in Sinapsis alba and Arabidopsis thaliana seedlings. Plant J, Vol.12, No.3, (September 1977), pp. 625-634.

Walter, MH.; Floss, D. \& Strack, D. (2010). Apocarotenoids: hormones, mycorrhizal metabolites and aroma volatiles. Planta, Vol.232, No.1, (April 2010), pp 1-17. 
Wang, H.; Ma LG.; Li, JM.; Zhao, HY. \& Deng, XW. (2001). Direct interaction of Arabidopsis cryptochromes with COP1 in light control development. Science, Vol.294, No.5540, (August 2001), pp.154-158.

Welsch, R.; Beyer, P.; Hugueney, P.; Kleinig, H. \& von Lintig, J. (2000). Regulation and activation of phytoene synthase, a key enzyme in carotenoid biosynthesis, during photomorphogenesis. Planta, Vol.211, No.6, (November 2000), pp.846-854.

Welsch, R.; Medina, J.; Giuliano, G.; Beyer, P. \& von Lintig, J. (2003). Structural and functional characterization of the phytoene synthase promoter from Arabidopsis thaliana. Planta, Vol.216, No.3, (January 2003), pp.523-534.

Woitsch, S. \& Römer, S. (2003). Expression of xanthophyll biosynthetic genes during lightdependent chloroplast differentiation. Plant Physiol, Vol.132, No.3, (July 2003), pp.1508-1517.

Yadav, V.; Kundu, S.; Chattopadhyay, D.; Negi, P.; Wei, N.; Deng, XW. \& Chattopadhyay, S. (2002). Light regulated modulation of Z-box containing promoters by photoreceptors and downstream regulatory components, COP1 and HY5, in Arabidopsis. Plant J, Vol.31, No.6, (September 2002), pp.741-753.

Yanawaga, J.; Sullivan, JA.; Komatsu, S.; Gusmaroli, G.; Suzuki, G.; Yin, J.; Ishibashi, T.; Saijo, Y. ; Rubio, V.; Kimura, S.; Wang, J. \& Deng, XW. (2004). Arabidopsis COP10 forms a complex with DDB1 and DET1 in vivo and enhances the activity of ubiquitin conjugating enzymes. Genes Dev, Vol.18, No.17, (September 2004), pp.2172-2181.

Yang, HQ.; Tang, RH. \& Cashmore, AR. (2001). The signalling mechanism of Arabidopsis CRY1 involves direct interaction with COP1. Plant Cell, Vol.13, No.12, (December 2001), pp.2573-2587.

Ye, X.; Al-Babili, S.; Klot, A.; Zhang, J.; Lucca, P.; Beyer, P. \& Potrycus, I. (2000). Engineering the provitamin A ( $\beta$-carotene) biosynthetic pathway into (carotenoid-free) rice endosperm. Science, Vol.287, No.5451, (January 2000), pp.303-305.

Zhu, C.; Yamamura, S.; Koiwa, H.; Nishihara, M. \& Sandmann, G. (2002). cDNA cloning and expression of carotenogenic genes during flower development in Gentiana lutea. Plant Mol Biol, Vol.48, No.3, (February 2002), pp.277-285.

Zhu, C.; Yamamura, S.; Nishihara, M.; Koiwa, H. \& Sandmann, G. (2003). cDNAs for the synthesis of cyclic carotenoids in petals of Gentiana lutea and their regulation during flower development. Biochem et Biophys Acta, Vol.1625, No.3, (February 2003), pp.305-308. 


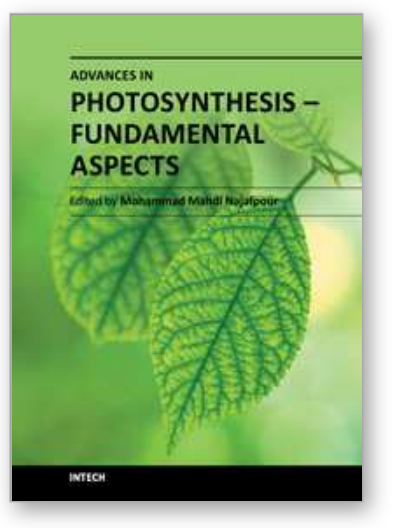

\section{Advances in Photosynthesis - Fundamental Aspects \\ Edited by Dr Mohammad Najafpour}

ISBN 978-953-307-928-8

Hard cover, 588 pages

Publisher InTech

Published online 15, February, 2012

Published in print edition February, 2012

Photosynthesis is one of the most important reactions on Earth. It is a scientific field that is the topic of many research groups. This book is aimed at providing the fundamental aspects of photosynthesis, and the results collected from different research groups. There are three sections in this book: light and photosynthesis, the path of carbon in photosynthesis, and special topics in photosynthesis. In each section important topics in the subject are discussed and (or) reviewed by experts in each book chapter.

\section{How to reference}

In order to correctly reference this scholarly work, feel free to copy and paste the following:

Claudia Stange and Carlos Flores (2012). Carotenoids and Photosynthesis - Regulation of Carotenoid Biosyntesis by Photoreceptors, Advances in Photosynthesis - Fundamental Aspects, Dr Mohammad Najafpour (Ed.), ISBN: 978-953-307-928-8, InTech, Available from: http://www.intechopen.com/books/advances-inphotosynthesis-fundamental-aspects/carotenoids-and-photosynthesis-regulation-of-carotenoid-biosyntesis-byphotoreceptors

\section{INTECH}

open science | open minds

\section{InTech Europe}

University Campus STeP Ri

Slavka Krautzeka 83/A

51000 Rijeka, Croatia

Phone: +385 (51) 770447

Fax: +385 (51) 686166

www.intechopen.com

\section{InTech China}

Unit 405, Office Block, Hotel Equatorial Shanghai

No.65, Yan An Road (West), Shanghai, 200040, China

中国上海市延安西路 65 号上海国际贵都大饭店办公楼 405 单元

Phone: +86-21-62489820

Fax: +86-21-62489821 
(C) 2012 The Author(s). Licensee IntechOpen. This is an open access article distributed under the terms of the Creative Commons Attribution 3.0 License, which permits unrestricted use, distribution, and reproduction in any medium, provided the original work is properly cited. 